\title{
FUNCTIONAL RESPIRATORY EVALUATION IN THE COVID-19 ERA: THE ROLE OF PULMONARY FUNCTION TEST LABORATORIES
}

\author{
Laura Gochicoa-Rangel ${ }^{1}$, Luis Torre-Bouscoulet ${ }^{2 *}$, Antonio Salles Rojas ${ }^{1}$, \\ Carlos Guzmán-Valderrábano ${ }^{1}$, Mónica Silva-Cerón ${ }^{1}$, Rosaura E. Benítez-Pérez ${ }^{3}$, \\ ISABel Salas-Escamilla ${ }^{1}$, Wilmer Madrid-Mejía ${ }^{1}$, and Juan M. Grosso-EsPinosa ${ }^{2}$
}

${ }^{1}$ Department of Respiratory Physiology, Instituto Nacional de Enfermedades Respiratorias "Ismael Cosío Villegas", Mexico City; 'Laboratory of Pulmonary Function Tests, Instituto de Desarrollo e Innovación en Fisiología Respiratoria, Mexico City; ${ }^{3}$ Department of Continuous Education, Instituto Nacional de Enfermedades Respiratorias "Ismael Cosío Villegas", Mexico City, Mexico

On behalf of the Latin-American Society of Respiratory Physiology (SOLAFIRE). All authors from SOLAFIRE contributed equally in this study.

\begin{abstract}
The pandemic character of coronavirus disease-19 (COVID-19) requires strategy changes designed to guarantee the safety of patients and health-care professionals. We are greatly concerned by the limitations in the operation of pulmonary function test (PFT) laboratories, since there is a high risk of disease progression in patients with chronic pulmonary diseases, and we are now faced by the influx of a new group of individuals in the recovery phase of post-COVID-19-syndrome that requires evaluation and follow-up of their respiratory function. To reestablish the operation of PFT laboratories limiting the risk of cross-contamination, we herein present the consensus reached by a group of experts in respiratory physiology, most of whom work in PFT laboratories in several Latin American countries, on the applicable recommendations for severe acute respiratory syndrome coronavirus 2 pneumonia survivors when undergoing PFT. We present the safety and hygiene measures that must be adopted in laboratories or centers where PFT is conducted in adults and/or children. These recommendations answer the following questions: which PFT is most recommended in subjects that have recovered from COVID-19; what quality control and safety measures should PFT laboratories implement during this pandemic? And how should we approach non-COVID-19 patients requiring PFT? (REV INVEST CLIN. [AHEAD OF PRINT])
\end{abstract}

Key words: Pulmonary function tests. Pulmonary function test laboratories. Quality and safety measures. COVID-19. SARS-CoV-2.

Note: This manuscript has been accepted for publication and has undergone an exceptional internal review process to expedite its dissemination as it dwells on urgent information of special interest regarding coronavirus disease- 19 .

*Corresponding author:

Luis Torre-Bouscoulet

E-mail: luis.torre@infire.mx
Received for publication: 27-05-2020

Approved for publication: 01-06-2020

DOI: $10.24875 / R I C .20000250$

0034-8376 / (c) 2020 Revista de Investigación Clínica. Published by Permanyer. This is an open access article under the CC BY-NC-ND license (http://creativecommons.org/licenses/by-nc-nd/4.0/). 


\section{INTRODUCTION}

Throughout the history of humankind, emergent respiratory diseases of infectious origin have arisen, leading to acute or chronic pulmonary damage with consequent abnormalities in respiratory mechanics and in the natural process of gas exchange ${ }^{1}$. In December 2019, a new coronavirus was described for the first time as one that can be transmitted among humans, and causing systemic disease of respiratory predominance that in some individuals, leads to progressive respiratory insufficiency and even death. The World Health Organization (WHO) named this disease Coronavirus Disease-19 (COVID-19) and the virus as severe acute respiratory syndrome coronavirus 2 (SARS-CoV-2) ${ }^{2}$. Individuals, who survive the severe forms of SARS-CoV-2 infection, could nevertheless have residual abnormalities - transitory or permanent - in respiratory function that must be evaluated in pulmonary function test (PFT) laboratories.

The pandemic character of COVID-19 has led to modifications in the safety procedures involved in the administration of health services and requires implementing strategy changes designed to guarantee the safety of both users and health personnel. We are greatly concerned that limitations in the operation of PFT laboratories resulting from this pandemic, may foster a high risk of disease progression and clinical deterioration in patients who suffer from chronic pulmonary disease; in addition, we are now faced by the influx of a new group of subjects that require pulmonary function evaluation and/or follow-up, namely, post-COVID-19-syndrome patients in the recovery phase. This entails the extremely difficult task of reestablishing the operations of PFT laboratories, limiting the risk of cross-contamination in personnel and patients.

This document presents the consensus reached by group of experts in respiratory physiology, most of whom work in PFT laboratories in various Latin American countries, and includes recommendations that should be implemented in survivors of SARS-CoV-2 infection, as well as safety and hygiene measures that must be adopted in laboratories or centers where PFT is performed in adults and/or children. The expressed recommendations reflect the experience and opinions of highly-qualified health professionals who work in centers with large patient flows, as well as information published by international experts. They are not meant to replace clinical judgment but rather, should be considered as suggestions to update our activities, as we learn more about this disease.

\section{PATHOGENIC MECHANISMS OF VIRAL RESPIRATORY INFECTIONS AND THEIR REPERCUSSIONS ON RESPIRATORY FUNCTION}

Acute respiratory infections caused by viruses (parainfluenza, rhinovirus, syncytial respiratory virus, influenza, coronavirus, and among others) ${ }^{3}$ cause an inflammatory process characterized by distinct physiopathological mechanisms that generate different clinical profiles depending on the microorganism involved and the conditions of the host. In spite of the innate and adaptive immune response that these infections trigger, these viruses may directly injure the respiratory epithelium, producing airway denudation, cell death (apoptosis and necrosis), and alveolar compromise. In smooth bronchial muscle, there may be dysfunction and early sensitization of the parasympathetic nerve endings that cause the $\mathrm{M} 2$ muscarinic acetylcholine receptors to lose their function ${ }^{4}$. Under these conditions, mechanical or chemical stimuli can trigger bronchoconstriction ${ }^{3-5}$ that results in an asthma-like clinical profile manifested by coughing and in some cases, wheezing in the post-infectious period.

From a functional perspective, when injury is minor, the results of mechanical respiratory tests like spirometry are characterized by a decrease in the forced exhaled volume at the halfway point of the $1^{\text {st }} \mathrm{s}$ $\left(\mathrm{FEV}_{0.5}\right)$ and in $1^{\text {st }} \mathrm{s}\left(\mathrm{FEV}_{1}\right)$, as well as of the $\mathrm{FEV}_{1}$ ratio of the forced vital capacity test (FVC) $-\mathrm{FEV}_{1} / \mathrm{FVC}$ accompanied by an increase in respiratory resistances at low frequencies, and greater negative reactance at $5 \mathrm{~Hz}\left(\mathrm{X}_{\mathrm{rs}} 5 \mathrm{~Hz}\right)^{6,7}$. This results in airway obstruction, exercise-induced bronchospasm and in some cases hypoxemia, manifested by a decreased pulmonary diffusion of carbon monoxide $\left(\mathrm{DL}_{\mathrm{CO}}\right)$, and abnormalities in the time constant. While in many cases this profile can be reverted in a lapse of 3-6 weeks, it may become persistent, especially if the disease occurs at an early pediatric age ${ }^{1,7-9}$. Adult patients with asthma or chronic obstructive pulmonary disease may suffer 
exacerbations due to these microorganisms and is manifested clinically as bronchospasm, and functionally as a decrease in $\mathrm{FEV}_{1}$ and exercise-induced bronchospasm that can last for up to 8 weeks ${ }^{1}$.

SARS-CoV causes sloughing of the bronchial epithelium, loss of cilia, scaly metaplasia, and infiltration of giant cells, with a marked increase in macrophages within the alveoli and interstitial space. This generates obliterative bronchiolitis, diffuse alveolar damage, and organized pneumonia. The pathogenesis of the coronavirus middle-east respiratory syndrome coronavirus (MERS-CoV) includes injury to types I and II pneumocytes, the ciliated bronchial epithelium, the non-ciliated cuboid cells of the terminal bronchioles, and the endothelial cells of pulmonary vessels ${ }^{10,11}$.

Both SARS-CoV and MERS-CoV can cause severe pneumonia and acute respiratory distress syndrome (ARDS) with variations in morbidity and mortality depending on the pathogenesis of each case ${ }^{10,12}$. Functional evaluation after the acute phase may be normal, or may show an obstructive or restrictive pattern of varying severity. The decrease in $\mathrm{DL}_{\mathrm{CO}}$ with low static pulmonary volumes and the distance covered on the 6-min walking test (6-MWT), all tend to be functional expressions of sequelae in the pulmonary interstitium ${ }^{13-16}$.

Studies that include survivors of SARS-CoV have demonstrated that $25-40 \%$ of participants had persistent abnormalities in respiratory function 1 year after their release from the hospital ${ }^{13,14}$. A 15-year follow-up study reported a persistent decrease in $\mathrm{DL}_{\mathrm{CO}}$ in $38.5 \%$ of patients ${ }^{15}$. This impairment in $\mathrm{DL}_{\mathrm{CO}}$ and consequently in exercise capacity has a more marked adverse effect on health-care workers ${ }^{17}$.

\section{PULMONARY INFECTION BY THE NEW CORONAVIRUS, SARS-COV-2}

The SARS-CoV-2 virus belongs to the genus Coronavirus and the family Coronaviridae, with a single-chain RNA and a genome size of approximately $30 \mathrm{~kb}^{17-19}$. The SARS-CoV-2 genome is similar to that of other coronavirus, such as SARS-CoV and MERS-CoV12,18. This genome encodes four structural proteins, among which the $\mathrm{S}$ protein is responsible for the binding and penetration of SARS-CoV-2 into the host's target cell, probably through the angiotensin-converting enzyme 2 receptor, expressed primarily in type II alveolar epithelial cells, and in other organs such as the heart, kidney, vascular epithelium, and intestine ${ }^{18}$. When the SARS-CoV-2 virus reaches the target cells, viral antigens are recognized through the antigen presenting cells to cytotoxic $T$ lymphocytes and activate CD4+ and CD8+ T cells.

Clinical characteristics vary from asymptomatic cases to mild respiratory disease or a SARS ${ }^{12}$. Among the factors promoting the development of ARDS caused by SARS-CoV-2, a reactive cytokine storm syndrome is pivotal; it is characterized by a generally lethal, uncontrollable inflammatory response that results in the release of pro-inflammatory cytokines (Interleukin [IL]-1 $\beta$, Interferon [IFN]- $\alpha$, IFN- $\gamma$, IL-12, IL-6, IL-18, tumor necrosis factor- $\alpha$, IL-33, transforming growth factor- $\beta$, etc.) and chemokines ( $C C L 3, C C L 2, C X C L 8$, CCL5, CXCL9, CXCL10, etc.) by immune cells ${ }^{16,18}$. Approximately $50 \%$ of patients develop a form of the disease that is treatment-resistant and those who survive have a high probability of developing pulmonary sequelae diagnosed by both imaging and PFT studies $^{19,20 .}$.

Postmortem studies have documented that individuals who suffered from COVID-19 can present diffuse alveolar disease with capillary congestion, necrosis of pneumocytes, hyaline membrane formation, interstitial edema, hyperplasia of pneumocytes, reactive atypia, as well as platelet thrombi with fibrin ${ }^{21}$. Due to the short time that has transpired since the appearance of this disease, the long-term impact of the pulmonary sequelae of SARS-CoV-2 cannot be determined, but reports from other countries confirm residual tomographic abnormalities in patients after hospital discharge (persistence of ground glass opacity $)^{22}$. Likewise, a recent report on non-critical patients found abnormalities in the $\mathrm{DL}_{\mathrm{CO}}$ in $47.2 \%$ of cases, with greater impairment as disease severity increased. It also referred abnormalities in pulmonary mechanics, such as a $25 \%$ reduction in total lung capacity, $13.6 \%$ reduction in $\mathrm{FEV}_{1}, 4.5 \%$ reduction in FVC, and abnormalities in the small airways in 7.3\% of patients ${ }^{23}$. Long-term pulmonary consequences of COVID-19 remain speculative, but the injuries that SARS-CoV-2 causes in the lung can herald the development of progressive and irreversible interstitial lung 
disease. It is therefore paramount to identify the potential development of pulmonary fibrosis in subjects who have recovered from COVID-1924.

\section{WHAT TESTS ARE MOST RECOMMENDED IN AN INDIVIDUAL THAT HAS RECOVERED FROM A COVID-19 INFECTION, AND WHEN SHOULD THEY BE INDICATED?}

Based on the existing scientific evidence of pulmonary sequelae in individuals who have recovered from SARS-CoV and MERS-CoV infections, as well as the early evidence obtained in SARS-CoV-2, performing mechanical respiratory and gas exchange tests are of utmost necessity. These tests should be performed 4-6 weeks after hospital discharge, ideally after a negative test for SARS-CoV-2. If possible, it is advisable to perform a cardiopulmonary exercise test, as this will permit the identification of factors limiting aerobic capacity and should be followed by an individualized respiratory rehabilitation program.

\section{Mechanical respiratory tests}

1. Spirometry with bronchodilator.

2. Impulse oscillometry.

3. Corporal plethysmography.

4. Maximum respiratory pressures (inspiratory and expiratory).

\section{Gas exchange tests}

1. Pulmonary diffusion of carbon monoxide, $\mathrm{DL}_{\mathrm{CO}}$.

2. Measurement of sat $\mathrm{O} 2$ or arterial gasometry.

3. Test of desaturation and titration of supplementary oxygen at rest and/or while exercising.

\section{Exercise tests}

1. Cardiopulmonary exercise test.

2. The 6-MWT.

\section{WHAT QUALITY CONTROL AND SAFETY MEASURES SHOULD RESPIRATORY FUNCTION LABORATORIES IMPLEMENT DURING THIS PANDEMIC?}

Performing PFT produces aerosolization of respiratory secretions, either because the individual coughs or sneezes, or due to the exhalation maneuver (sometimes forced) that these tests require. PFT laboratories have adopted certain international recommendations to ensure the safety of both users and personnel; however, as we confront the COVID-19 pandemic, it is important to (1) intensify safety measures to control the risk of cross-contamination, and (2) modify the logistics of the operative processes employed in the day-to-day functioning of these installations.

While it has been suggested that the level of safety depends on disease prevalence ${ }^{25}$, we consider that until there is a treatment capable of curing the disease or a vaccine to prevent it, all PFT centers must implement special safety measures when caring for their patients, due to the risk of contamination of the personnel, and the ever-present risk of cross-contamination through the employed measuring equipment. Before re-initiating work in a PFT laboratory, it is necessary to develop strategic planning that will involve the hospital's or institution's administration staff, considering that the costs to perform each test will increase. This planning must center on preventing and managing infections and must include training of all personnel in the new safety measures that are to be implemented ${ }^{26}$.

\section{PREPARING THE SITE AND GENERAL CONSIDERATIONS BEFORE EVALUATING STUDY SUBJECTS ${ }^{25-27}$ (TABLE S1)}

\section{Scheduling appointments}

1. Consider that more time will be required to test each patient, since the rooms and devices need to be decontaminated at the end of each test. Hence, when scheduling appointments, increase the time allotted to each patient as well as the period between patients. 
2. When scheduling appointments, it is important to be informed and register whether or not the patient suffered COVID-19. If affirmative, the appointment should be scheduled at least 6 weeks after she/he was discharged. It is also necessary to register whether there is a possibility that the individual had recent contact with a COVID-19 patient.

3. The recommendation is that whenever possible, in cases of patients who have had COVID-19, a negative polymerase chain reaction (PCR) test for SARS-CoV-2 should be obtained and recorded before scheduling an appointment for respiratory function tests.

4. On the day of the appointment, the patient will be instructed to arrive with a facemask that covers the nose and mouth. Preferably, she/he will come alone, or with a maximum of one companion, but only if strictly necessary (primary caregiver or family member).

5. We suggest sending videos to patients on how respiratory function tests are performed and that they should watch before their appointment, so as to become familiar with the procedures involved. This will decrease the time they need to spend in the laboratory. These are links for some PFT:

- Spirometry: https://youtu.be/uAo0RFpIM1A.

- DLCO: https://youtu.be/O8aVA4RMLks.

- The 6MWT: https://youtu.be/amNBffFyWCW.

\section{INFRASTRUCTURE}

1. Coordinate with the Department of Biosafety and Civil Protection, or an analogous committee, to plan the route that patients will follow to enter the hospital, institution, or office, to prevent contact with other patients and their companions.

2. If possible, a single area should be designated for patient care if they previously developed COVID-19, or they could be scheduled on exclusive days.

3. Visibly indicate a hygiene service (restroom) for the exclusive use of patients.
4. Coordinate with the maintenance service to program procedures to ensure the hygiene, disinfection, and thorough cleaning of the laboratory.

5. The waiting room should be reconditioned to ensure that it is well-ventilated, preferably lit with natural light, with the seats or chairs separated by at least $2 \mathrm{~m}$. Ideally, this room will be separate from the site where PFT is performed.

6. The laboratory must be well-ventilated with at least 6 changes of air/hour. Ideally, it will be equipped with a negative pressure system. Either ultraviolet light or ozone can be used for decontamination, but ozone requires great care because it can cause airway irritation. The utilization of high efficiency particulate air filters is still subject to debate due to their potential for colonization ${ }^{25}$.

7. The workstations where studies are performed must be separated to ensure that only one patient enters the area at a time. These zones should also be marked with a separation distance of $2 \mathrm{~m}$.

8. After each patient leaves, the testing area must be thoroughly cleaned and disinfected, as well as all the medical equipment used during testing.

9. Disinfection can be performed with glutaraldehyde-based formulations ( $2 \%$ ); stabilized hydrogen peroxide (6\%); peracetic acid (variable concentrations, but $\leq 1 \%$ is sporicidal); and sodium hypochlorite $(5.25 \%$, diluted to $1000 \mathrm{ppm}$ available chlorine $-1: 50$ dilution) ${ }^{30}$.

10. Ensure that the entire PFT laboratory is sanitized on a daily basis.

\section{MEASURING EQUIPMENT AND CONSUMABLES}

1. Carefully perform the established hygiene procedures in the PFT laboratory including washing, disinfecting, and/or sterilizing all reusable medical equipment and devices before they are used with the next patient. 
2. Perform calibration (or verification) of all respiratory function testing equipment in full compliance with the requirements established in national and international standardization guidelines before performing tests with patients.

3. In all cases, it is necessary to use a filter with a viral/bacterial filtration efficiency of $99.9 \%$ when performing PFT. The filter must have a certificate of efficiency approved for viruses and bacteria and must also prove efficient with expiratory flows up to $600-700 \mathrm{~L} / \mathrm{m}$. Using nozzles without filters are not recommended.

4. In the case of studies requiring equipment that utilizes sampling lines for gas analysis, these lines must be removed, cleaned, and disinfected, including the connector at the end of the cannula. If secretions are found - if possible - personal protective equipment (PPE) should be used to apply compressed air to eliminate them. Alcohol should not be injected in an attempt to disinfect ${ }^{27}$.

5. In the case of pulmonary function devices equipped with a pneumotachograph or turbine, these must be disinfected (or changed) before use in every patient. In addition, the medical devices used for PFT must be re-calibrated. This time period must be taken into account for the adequate scheduling of appointments.

6. It is important to provide alcohol gel in all workstations as well as tissues or paper towels.

7. All consumables must be discarded, including nasal forceps, spacers, adaptors, mouthpieces, nozzles, and filters.

8. All reusable devices must be handled as "contaminated material;" therefore, the recommendations for disinfection suggested by the manufacturer and all local infection control guidelines must be followed.

\section{PERSONAL PROTECTIVE EQUIPMENT FOR HEALTH PERSONNEL}

All health personnel must use personal protective equipment in accordance with their functions and in relation with disease prevalence. We suggest first, to coordinate with the department of biosafety to analyze the functions of all personnel, and then officially issue the PPE to be used by the administrative, medical, and technical personnel, according to the activities they perform.

According to the Centers for Disease Control and Prevention (CDC), SARS-CoV-2 is a pathogen of respiratory transmission that has the potential to cause serious injury and/or death. For this reason, the level of biosafety that must be maintained in the sites where there is potential for contamination by this pathogen, are 3 or $4^{28}$, and the PPE recommended for the personnel that comes into direct contact with respiratory aerosols under these conditions are as follows: (Table S2):

1. Sealed goggles or facemask.

2. High-efficiency mouth cover or facemask, N95, or equivalent.

3. Cap to cover hair.

4. Disposable gloves that must be changed between patients.

5. Surgical scrubs or work clothes, preferably disposable, or waterproof.

6. Perform hygiene measures or disinfection of the hands and/or gloves to decrease the risk of infections associated with medical care, using the correct technique - the 5 moments - issued by the World Health Organization (WHO) and as often as is necessary ${ }^{29}$, that is:

a. Before touching a patient.

b. Before performing a cleaning/septic task.

c. After risk or exposure to bodily fluids.

d. After touching a patient.

e. After contact with the patient's environment.

7. The health personnel that perform respiratory function tests must change certain items of their PPE (gloves, and scrubs) before testing each patient. 


\section{PATIENT CARE AND PERFORMING RESPIRATORY FUNCTION TESTS}

1. Extended time must be allowed for each patient who is to be tested. This will avoid prolonging the time people stay in the waiting room where there is a risk of contagion. The time required to perform the adequate cleaning and disinfection of the physical area and all medical equipment must also be considered before the next patient can be brought in for her/his studies.

2. Ensure the correct identification of each patient BEFORE performing any respiratory function tests.

3. A health questionnaire must be applied and filled out before any testing is done. Table S3 presents an example of a suitable health questionnaire designed to evaluate risk.

4. Based on the results of this questionnaire, patients can be classified as low- or high-risk ${ }^{27}$.

\section{Low-risk}

- Asymptomatic patients.

- Patients with no recent contact with individuals that are or have been ill.

- Patients with respiratory symptoms consistent with a pre-existing chronic pulmonary disease.

- Low disease prevalence in the locality.

\section{High-risk}

- New or multiple respiratory symptoms.

- III Individuals within the household.

- Fever.

- Health personnel (nurses, doctors, residents, and technicians).

- Processed food workers.

- Employees/workers in "essential" businesses.
1. The personnel responsible for performing PFT must verify that the patient does not present any contraindications and is in suitable conditions to undergo testing before beginning any clinical study.

2. If a patient is suspected of having COVID-19, it is necessary to cancel testing and reschedule the appointment when she/he has a negative PCR test for SARS-CoV-2, or after a period of 4-6 weeks after the end of treatment.

3. Verify that patients follow hygienic hand-washing measures on entering the health center.

4. Position both the technician's and the patient's chairs in the same direction to avoid face-to-face interaction during maneuvers.

5. The technician who runs the tests must never remove her/his protective mouth cover or facemask during the testing process ${ }^{26}$.

6. Conduct all respiratory function tests in strict accordance with procedure manuals and comply with all requirements stipulated in international standardization guidelines as well as local recommendations.

7. The results of all respiratory function tests must be validated and interpreted by qualified personnel.

8. The results of the tests, their interpretation and all recommendations must be provided to the patient; however, it is preferable to avoid issuing written reports. We recommend using electronic means to forward all documents issued by the physician who interprets and validates testing.

\section{WHAT TO DO WITH SUBJECTS WHO HAVE NOT HAD COVID-19 BUT REQUIRE RESPIRATORY FUNCTION TESTS?}

Due to the nature of this disease, patients who have not had COVID-19 but require PFT must be handled as potentially asymptomatic carriers of SARS-CoV-2. Therefore, exactly the same safety guidelines for disease control must be followed, and the same health 
questionnaire must be applied before performing any respiratory function test.

We recommend that the physician who cares for patients with a chronic respiratory disease, only ask for essential PFT int his individuals. In the event that these require administering a bronchodilator, this must be done with a spacer and only using inhalers that provide a metered dose inhaler (MDI). We suggest requesting that the patient brings her/his own MDI but if this is not possible, the device must be decontaminated before it can be used on another individual. Whenever possible, spirometry should be performed in the patient's home, should she/he require follow-up.

\section{Cases in which respiratory function tests are essential ${ }^{27}$}

- Evaluation of patients for transplant or pulmonary resection.

- Monitoring for cases of obliterative bronchiolitis in transplanted patients.

- Evaluation of pre-operative risk.

- Diagnosing dyspnea.

- Monitoring patients who are at risk of drug-induced pulmonary toxicity.

- Before beginning drug therapy or changing an existing treatment, especially if the drugs required are costly (e.g., antifibrotics).

Exercise tests such as cardiopulmonary exercise test, bronchial challenge, or bronchoprovocation with exercise procedures, ventilatory control tests, and tests that require nebulizations - such as bronchial challenge with methacholine - must be avoided as far as possible because (i) they generate aerosols; (ii) the required maneuvers are difficult to perform; and (iii) there is a possibility of errors in measurement since these studies require the use of filters. In cases in which such tests are essential, we initially suggest documenting that the PCR test for SARS-CoV-2 is negative and second, ensuring that the personnel who conduct the test use the appropriate PPE, as stipulated above.

\section{CONCLUSION}

In spite of decreased disease prevalence in a specific area, until we can count on an effective COVID-19 treatment or vaccine to immunize health personnel, these tests will continue to be conducted in strict accordance with the hygienic measures stipulated herein, utilizing personal protection equipment at all times.

\section{ACKNOWLEDGMENTS}

We are grateful to Ana Sofia Grosso, for the handmade pictures shown in table S3.

\section{SUPPLEMENTARY DATA}

Supplementary data are available at Revista de Investigación Clínica online (www.clinicalandtranslationalinvestigation.com). These data are provided by the corresponding author and published online for the benefit of the reader. The contents of supplementary data are the sole responsibility of the authors.

\section{Latin-American SOCIETY OF RESPIRATORY PHYSIOLOGY (SOLAFIRE)}

Silvia Cid-Juárez (Department of Respiratory Physiology. Instituto Nacional de Enfermedades Respiratorias "Ismael Cosío Villegas." Mexico City, Mexico), Sergio-Monraz Pérez (Coordination of Medical Care. Instituto Nacional de Enfermedades Respiratorias "Ismael Cosío Villegas." Mexico City, Mexico), Viridiana Vega-Salazar (Laboratory of PFT. Instituto de Desarrollo e Innovación en Fisiología Respiratoria. Mexico City, Mexico), Ada De Los Santos Martínez (Laboratory of PFT. Instituto de Desarrollo e Innovación en Fisiología Respiratoria. Mexico City, Mexico), Federico Hernández-Rocha (BreathBaja, Department of Physiology and Respiratory Therapy. Baja California. Mexico), Omar CeballosZúñiga (BreathBaja, Department of Physiology and Respiratory Therapy. Baja California, Mexico), Ireri 
Thirión-Romero (Smoking Clinic. Instituto Nacional de Enfermedades Respiratorias. "Ismael Cosío Villegas." Mexico City, México), Irma Lechuga Trejo (Respiratory Physiology. Hospital Regional de Alta Especialidad de Ixtapaluca. Ixtapaluca, México), Antonio Plutarco Arias (Sleep Apnea Institute (INAPS). Clínica Unión Médica del Norte. Santiago De Los Caballeros, Dominican Republic), Rosa Fernández Hawa (Sleep Apnea Institute (INAPS). Clínica Unión Médica del Norte. Santiago De Los Caballeros, Dominican Republic), Gisela Burgoa-Gutiérrez (National Thorax Institute. La Paz, Bolivia), Arturo Cortés-Telles (Laboratory of Respiratory Physiology. Hospital Regional de Alta Especialidad de la Península de Yucatán. Yucatán. Mexico), Carlos Aguirre (Laboratory of Pulmonary Function. Fundación Neumológica Colombiana. Bogotá, Colombia), Gabriela Cantú González (Laboratory of Pulmonary Function. Hospital Zambrano Hellion Tec Salud. Nuevo León, Mexico), Armando Castorena-Maldonado (Laboratory of Nose. Instituto Nacional de Enfermedades Respiratorias "Ismael Cosío Villegas." Mexico City, Mexico), Carmen Hernández-Cárdenas (Respiratory Intensive Care Unit. Instituto Nacional de Enfermedades Respiratorias "Ismael Cosío Villegas." Mexico City, Mexico) Luis Felipe Jurado-Camacho (Respiratory Intensive Care Unit. Instituto Nacional de Enfermedades Respiratorias "Ismael Cosío Villegas." Mexico City, Mexico), Luciano Enrique Busi (Pulmonary Disease Unit, Hospital de Trelew. Trelew. Chubut, Argentina), Luisa Fernanda MartínezValdeavellano (Department of Pediatric Pulmonary Disease, Instituto Guatemalteco de Seguridad Social. Guatemala, Guatemala) Ana Karen Gutiérrez (Hospital de Pediatría. Unidad Médica de Alta Especialidad. Siglo XXI. Mexico City, Mexico), Mónica Velázquez Uncal (Hospital General "Dr. Miguel Silva." Morelia, Michoacán. Mexico) Manuel Arnoldo Mejía-Escobar (Hospital Médico Quirúrgico y Oncología. Instituto Salvadoreño del Seguro Social. San Salvador. El Salvador), Rocío Arruabarrena (National Institute of Respiratory Disease and Environment - INERAM. Asunción, Paraguay), María René Alvarez-Arroyo (Pediatrics Service. Hospital Materno Pediátrico de Xochimilco. Xochimilco, Mexico City, Mexico), Johanna Karina Navarrete-Rivera (Pediatrics Service. Hospital Militar Escuela "Dr. Alejandro Davila Bolaños. Managua, Nicaragua), Selene Guerrero Zúñiga (Sleep Medicine Unit. Instituto Nacional de Enfermedades Respiratorias "Ismael Cosío Villegas." Mexico City, Mexico).

\section{REFERENCES}

1. Hall W, Hall CB. Clinical significance of pulmonary function tests. Chest. 1979;76:458-65.

2. Worl Health Organization. Coronavirus Disease 2019. Naming the Coronavirus Disease (COVID-19) and the Virus that Causes it 2020. Available from: https://www.who.int/emergencies/ diseases/novel-coronavirus-2019/technical-guidance/namingthe-coronavirus-disease-(covid-2019)-and-the-virus-thatcauses-it. [Last accessed on 2020 May 19].

3 . Busse $W$. The role of respiratory infections in airway hyperresponsiveness and asthma. Am J Respir Crit Care Med. 1994 150:S77-9.

4. Fryer AD, El-Fakahany EE, Jacoby DB. Parainfluenza virus Type 1 reduces the affinity of agonists for muscarinic receptors in guinea-pig lung and heart. Eur J Pharmacol. 1990;181:51-8.

5. Jacoby DB, Fryer AD. Abnormalities in neural control of smooth muscle in virus-infected airways. Trends Pharmacol Sci. 1990; 11:393-5

6. Guilbert TW, Singh AM, Danov Z, Evans MD, Jackson DJ, Burton $R$, et al. Decreased lung function after preschool wheezing rhinovirus illnesses in children at risk to develop asthma. J Allergy Clin Immunol. 2011;128:532-8, e1-10.

7. Strope GL, Stewart PW, Henderson FW, Ivins SS, Stedman HC, Henry MM. Lung function in school-age children who had mild lower respiratory illnesses in early childhood. Am Rev Respir Dis. 1991; 144:655-62.

8. Zomer-Kooijker K, van der Ent CK, Ermers MJ, Uiterwaal CS, Rovers MM, Bont LJ, et al. Increased risk of wheeze and decreased lung function after respiratory syncytial virus infection. PLoS One. 2014;9:e87162.

9. Riikonen R, Lauhkonen E, Tormanen S, Backman K, Koponen P, Helminen M, et al. Prospective study confirms that bronchiolitis in early infancy increases the risk of reduced lung function at 10-13 years of age. Acta Paediatr. 2019;108:124-30

10. Hui DS. Epidemic and emerging coronaviruses (severe acute respiratory syndrome and middle east respiratory syndrome). Clin Chest Med. 2017;38:71-86.

11. Guarner J. Three emerging coronaviruses in two decades. Am J Clin Pathol. 2020;153:420-1.

12. Meo SA, Alhowikan AM, Al-Khlaiwi T, Meo IM, Halepoto DM, Iqbal M, et al. Novel coronavirus 2019-nCoV: prevalence, biological and clinical characteristics comparison with SARS-CoV and MERS-CoV. Eur Rev Med Pharmacol Sci. 2020;24:2012-9.

13. Ong KC, Ng AW, Lee LS, Kaw G, Kwek SK, Leow MK, et al. 1-Year pulmonary function and health status in survivors of severe acute respiratory syndrome. Chest. 2005;128:1393-400.

14. Hui DS, Wong KT, Ko FW, Tam LS, Chan DP, Woo J, et al. The 1-year impact of severe acute respiratory syndrome on pulmonary function, exercise capacity, and quality of life in a cohort of survivors. Chest. 2005;128:2247-61.

15. Zhang P, Li J, Liu H, Han N, Ju J, Kou Y, et al. Long-term bone and lung consequences associated with hospital-acquired severe acute respiratory syndrome: a 15-year follow-up from a prospective cohort study. Bone Res. 2020;8:8.

16. Li L, Xin S, Qi W, Qian W, Zhihang X, Hongzhi Y. The lung function status in patients with SARS after ten years of convalescence in Tianjin. Agosto 2015. Chin J Tuberc Respir Dis. 2015;38:575-8.

17. Ngai JC, Ko FW, Ng SS, To KW, Tong M, Hui DS. The long-term impact of severe acute respiratory syndrome on pulmonary function, exercise capacity and health status. Respirology. 2010:15:543-50

18. Saxena SK. Coronavirus Disease 2019-COVID_19: Epidemiology Pathogenesis Diagnosis and Therapeutics. Singapore: Springer 2020. p. 213

19. Lai CC, Shih TP, Ko WC, Tang HJ, Hsueh PR. Severe acute respiratory syndrome coronavirus 2 (SARS-CoV-2) and coronavirus disease-2019 (COVID-19): the epidemic and the challenges. Int J Antimicrob Agents. 2020;55:105924.

20. Mo P, Xing Y, Xiao Y, Deng L, Zhao Q, Wang $H$, et al. Clinical characteristics of refractory COVID-19 pneumonia in Wuhan, China. Clin Infect Dis. 2020; ciaa270.

21. Carsana L, Sonzogni A, Nasr A, Rossi RS, Pellegrinelli A, Zerbi P, et al. Pulmonary Post-mortem Findings in a Large Series of COVID-19 Cases from Northern Italy; 2020. Available from: https://www.medrxiv.org/content/10.1101/2020.04.19.200 54262v1.full.pdf+html. [Last accessed on 2020 May 26].

22. Wang Y, Dong C, Hu Y, Li C, Ren Q, Zhang X, et al. Temporal changes of CT findings in 90 patients with COVID-19 pneumonia: a longitudinal study. Radiology. 2020;[Epub ahead of print]. 
23. Mo X, Jian W, Su Z, Chen M, Peng H, Peng $P$, et al. Abnormal pulmonary function in COVID-19 patients at time of hospital discharge. Eur Repir J. 2020; [Epub ahead of print].

24. Spagnolo $P$, Balestro E, Aliberti S, Cocconcelli E, Biondini D, Casa GD, et al. Pulmonary fibrosis secondary to COVID-19: a call to arms? Lancet Respir Med. 2020;S2213-2600(20)30222-8.

25. McGowan A, Sylvester K, Burgos F, Boros P, De-Jongh F, Kendrick A, et al. Recommendation from ERS Group 9.1 (Respiratory Function Technologists/Scientists) Lung Function Testing During COVID-19 Pandemic and Beyond; 2020. Available from: https://www.ers.app.box.com/s/zs 1 uu 88 wy 51 monr0ewd990itoz4tsn2h. [Last accessed on 2020 May 24].

26. Task Force of Pulmonary Function Testing and Clinical Respiratory Physiology, Chinese Association of Chest Physicians; Pulmonary Function Testing Group, Respiratory Therapeutics Group, Chinese Thoracic Society. Expert consensus on pulmonary function testing during the epidemic of corona virus disease 2019. Zhonghua Jie He He Hu Xi Za Zhi. 2020;43: 302-7.

27. O'Brien M. Restarting Your Lab-a Pathway to Resuming Diagnostic Testing A Webinar; 2020. Available from: https://www. youtube.com/watch?v=pSxCEGUkCSO\&feature=youtu.be [Last accessed on 2020 May 21].

28. Centers for Disease Control and Prevention. Recognizing the Biosafety Levels. Quick Learn Lessons; 2020. Available from: https://www.cdc.gov/training/quicklearns/biosafety. [Last accessed on 2020 May 16].

29. World Health Organization. Indicaciones Para la Higiene de las Manos. Available from: https://www.who.int/gpsc/tools/Five moments/es. [Last accessed on 2020 May 20].

30. World Health Organization. Annex I cleaning and disinfection of respiratory equipment. In: Infection Prevention and Control of
Epidemic-and Pandemic-prone Acute Respiratory Infections in Health Care. Geneva: World Health Organization; 2014. Available from: https://www.ncbi.nlm.nih.gov/books/NBK214361. [Last accessed on 2020 May 27].

31. Yan Y, Chen H, Chen L, Cheng B, Diao P, Dong L, et al. Consensus of Chinese experts on protection of skin and mucous membrane barrier for health-care workers fighting against coronavirus disease 2019. Dermatol Ther. 2020;e13310.

32. Zhou W, Zhong N. The Coronavirus Prevention Handbook: 101 Science-based Tips that Could Save Your Life. New York: Skyhorse Publishing; 2020.

33. Centers for Disease Control and Prevention. Infection Control Guidance for Healthcare Professionals about Coronavirus (COVID-19); 2020. Available from: https://www.cdc.gov/ coronavirus/2019-ncov/hcp/infection-control.html. [Last accessed on 2020 May 16].

34. Lindsley WG, Noti JD, Blachere FM, Szalajda JV, Beezhold DH Efficacy of face shields against cough aerosol droplets from a cough simulator. J Occup Environ Hyg. 2014;11:509-18.

35. Occupational Safety and Health Administration. United States Department of Labor. Tipos de Respiradores. Available from https://www.osha.gov/video/respiratory_protection/resptypes_sp_transcript.html. [Last accessed on 2020 May 16].

36. Centers for Disease Control and Prevention. Interim Infection Prevention and Control Recommendations for Patients with Suspected or Confirmed Coronavirus Disease 2019 (COVID-19) in Healthcare Settings; 2020. Available from: https://www.cdc. gov/coronavirus/2019-ncov/hcp/infection-control-recommendations.html?CDC AA refVal=https $\% 3 \mathrm{~A} \% 2 \mathrm{~F} \% 2 \mathrm{Fwww} . \mathrm{cdc}$. gov \% 2 Fcoronavirus \% 2 F 2019 -ncov\% 2 Finfectioncontrol\%2Fcontrol-recommendations.html. [Last accessed on 2020 May 16]. 


\section{FUNCTIONAL RESPIRATORY EVALUATION IN THE COVID-19 ERA: THE ROLE OF PULMONARY FUNCTION TEST LABORATORIES}

Laura Gochicoa-Rangel ${ }^{1}$, Luis TorRe-Bouscoulet ${ }^{2 *}$, Antonio Salles Rojas ${ }^{1}$

Carlos Guzmán-Valderrábano ${ }^{1}$, Mónica Silva-Cerón ${ }^{1}$, Rosaura E. Benítez-Pérez ${ }^{3}$,

Isabel Salas-Escamilla ${ }^{1}$, Wilmer Madrid-Mejía ${ }^{1}$, and Juan M. Grosso-Espinosa ${ }^{2}$

${ }^{1}$ Department of Respiratory Physiology, Instituto Nacional de Enfermedades Respiratorias "Ismael Cosío Villegas", Mexico City; 2Laboratory of Pulmonary Function Tests, Instituto de Desarrollo e Innovación en Fisiología Respiratoria Mexico City; ${ }^{3}$ Department of Continuous Education, Instituto Nacional de Enfermedades Respiratorias "Ismael Cosío Villegas", Mexico City, Mexico

On behalf of the Latin-American Society of Respiratory Physiology (SOLAFIRE). All authors from SOLAFIRE contributed equally in this study.

Table S1. Checklist of resources and activities before reinitiating activities in a PFT lab

\begin{tabular}{|c|c|c|}
\hline Patient appointment & YES & NO \\
\hline $\begin{array}{l}\text { 1. Increase time allotted to each patient and schedule appointments with prolonged intervals } \\
\text { between patients }\end{array}$ & & \\
\hline $\begin{array}{l}\text { 2. Elaborate a short questionnaire to identify symptoms that may suggest COVID-19 } \\
\text { (Table 4) }\end{array}$ & & \\
\hline 3. Secure a system procedure for patient referral for SARS-CoV-2 detection & & \\
\hline $\begin{array}{l}\text { 4. Elaborate a document with instructions for patients stipulating that they are to arrive } \\
\text { at the PFT lab preferably alone, and with a facemask covering the mouth and nose; this } \\
\text { document should be sent electronically to each patient }\end{array}$ & & \\
\hline $\begin{array}{l}\text { 5. Obtain instructive videos on how PFTs are performed and if possible, forward to patients } \\
\text { by e-mail }\end{array}$ & & \\
\hline
\end{tabular}

\section{Infrastructure}

1. Define and outline the route that patients are to follow in the hospital, institution or office

2. Assign and indicate in a visible manner, the location of a hygiene service exclusive for patients (restroom)

3. Elaborate a written plan for suitable sanitation systems, and exhaustive hygiene and disinfection measures applied to all areas

4. The waiting room must be adequately reconditioned with clear indications on the distance to be maintained between patients

5. Verify that the respiratory function test laboratory has adequate ventilation

6. Ensure the adequate separation of all workstations, with at least $2 \mathrm{~m}$ between patients

7. Ensure adequate stocks of all implements and clear instructions on the procedures required to disinfect all work equipment and instruments

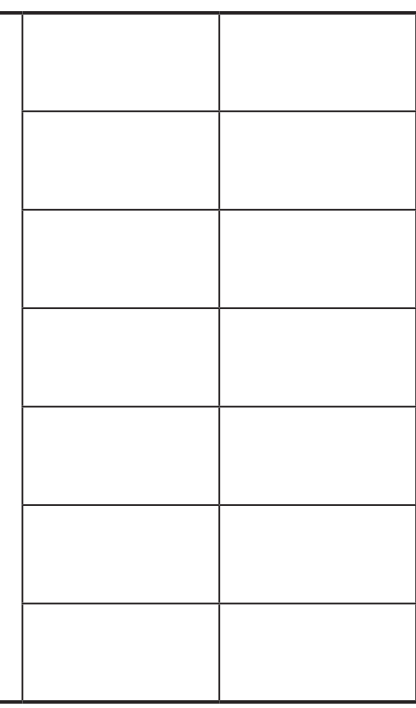

Measuring equipment and consumables

1. Ensure an adequate stock of certified filters required for respiratory function tests

2. Identify the systems for sampling gases and perform adequate disinfection procedures

3. Keep stocks of pneumotachographs and turbine systems; consider that these sensors will need re-calibration or re-verification of calibration as part of the center's standard operating procedures, between each patient

4. Ensure the availability of adequate personal protection equipment (PPE)

5. Ensure adequate stocks of alcohol gel or disinfection solution at all workstations

6. Verify stocks of disposable devices (nasal forceps, spacers, adapters, etc.)

7. Provide disposable tissues in all workstations

8. Ensure that all procedures for the hygiene, disinfection, washing, and/or sterilization of medical equipment and reusable materials are strictly followed

9. Ensure an electronic system to forward results and test interpretation to patients

\section{Protection of health personnel}

1. Obtain official biosafety recommendations for the administrative, technical, medical, and care providing personnel

2. Ensure the availability of PPE for all personnel according to their specific activities

3. Provide all personnel with training on the correct use of PPE

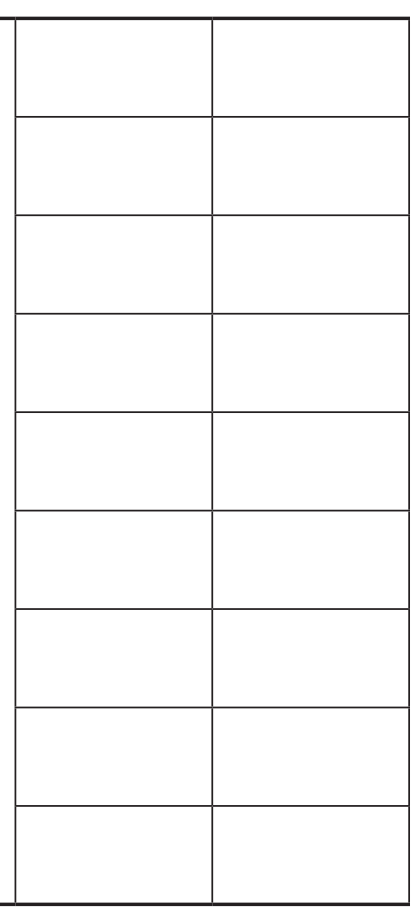

PFT: pulmonary function test.

Note: This manuscript has been accepted for publication and has undergone an exceptional internal review process to expedite its dissemination as it dwells on urgent information of special interest regarding coronavirus disease-19.

\section{*Corresponding author:}

Luis Torre-Bouscoulet

E-mail: luis.torre@infire.mx

Received for publication: 27-05-2020 Approved for publication: 01-06-2020 DOI: $10.24875 /$ RIC.20000250

0034-8376 / @ 2020 Revista de Investigación Clínica. Published by Permanyer. This is an open access article under the CC BY-NC-ND license (http://creativecommons.org/licenses/by-nc-nd/4.0/) 
Table S2. Personal protection equipment

\begin{tabular}{|c|c|c|c|}
\hline $\begin{array}{l}\text { Type of protection/ } \\
\text { anatomical region }\end{array}$ & Illustrative images & Description & Evidence and recommendations \\
\hline \multirow[t]{3}{*}{$\begin{array}{l}\text { Protection of head, } \\
\text { hair and ears }\end{array}$} & & $\begin{array}{l}\text { Disposable, liquid-resistant } \\
\text { surgical cap with elastic }\end{array}$ & $\begin{array}{l}\text { - Short hair is recommended; if hair is } \\
\text { long, it must be tightly held in place }\end{array}$ \\
\hline & & & - No earrings \\
\hline & & & $\begin{array}{l}\text { - The surgical cap must completely } \\
\text { cover the hair and ears }{ }^{31}\end{array}$ \\
\hline
\end{tabular}

Ocular protection

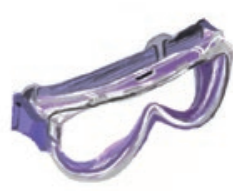

Hermetic goggles with

indirect ventilation

and an adjustable

The main objective of using goggles is to prevent infections caused by contact of aerosols with the ocular conjunctiva

- Goggles must completely and hermetically cover the eyes and periocular skin, but without generating excessive pressure

Respirator, mouth cover or high-efficiency mask

- The N95 respirator is a piece of respiratory protection equipment designed to produce a seal with the face (covering both nose and mouth). It efficiently filters $95 \%$ of particles 0.3 microns in size. It is certified by $\mathrm{NIOSH}$ for use by sanitary personne

- The N95's filtration efficiency is greater than that of surgical masks; however, even when used correctly,

With valve

Those with respiration valves reduce heat accumulation

- The filtration efficiency of both types is the same; however, the expiration valve type allows exhalation of bacteria or viruses so it does not protect individuals near an infected

Mask respirator

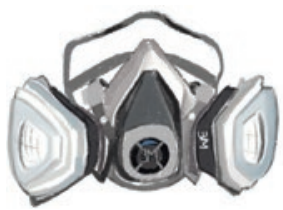

with N95 filters

- Mask-type respirators are more ergonomic and comfortable for workdays, have an exhalation valve, and come with replaceable filters

Facial protection

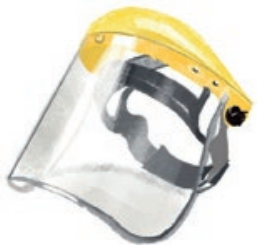

Safety helmet with facia protection

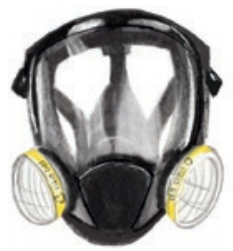

Complete mask-type elastomeric respirator

Protection of hands

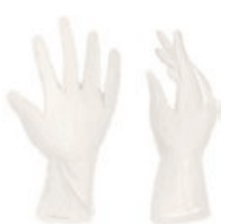

latex gloves

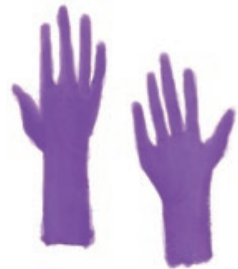
nitrile gloves

- Unsealed face-masks only decrease the immediate risk of exposure, not the risk when aerosols are dispersed in the environment. For this reason, we recommend using these masks with other respiratory protection (N95 or equivalent) and ocular protection (goggles), not as a

- Half- or full-mask elastomeric respirators have several filters for air and/or substances. They are hermetically-sealed and have interchangeable filters (for particulate materials) or cartridges (for gases and vapors). Whatever the case they are adjusted to a rubber or silicone mask that covers the face and generates a seal. This type of test and can be used with cant equipped with $\mathrm{N} 95$ filters ${ }^{35}$

- Double gloving is recommended - Gloves can be of the non-sterile type unless a sterile surgical procedure is required. In this case, the second pair must be sterile ${ }^{36}$

- Gloves should be removed using a technique that does not produce

- Nitrile gloves are recommended in case of allergies to latex ${ }^{36}$

- Use waterproof or liquid-resistant scrubs to provide protection against sealed seams and long sleeves that end with elastic not cotton cuffs 
Table S3. Sample questionnaire on health and risk evaluation before performing respiratory function tests ${ }^{25}$

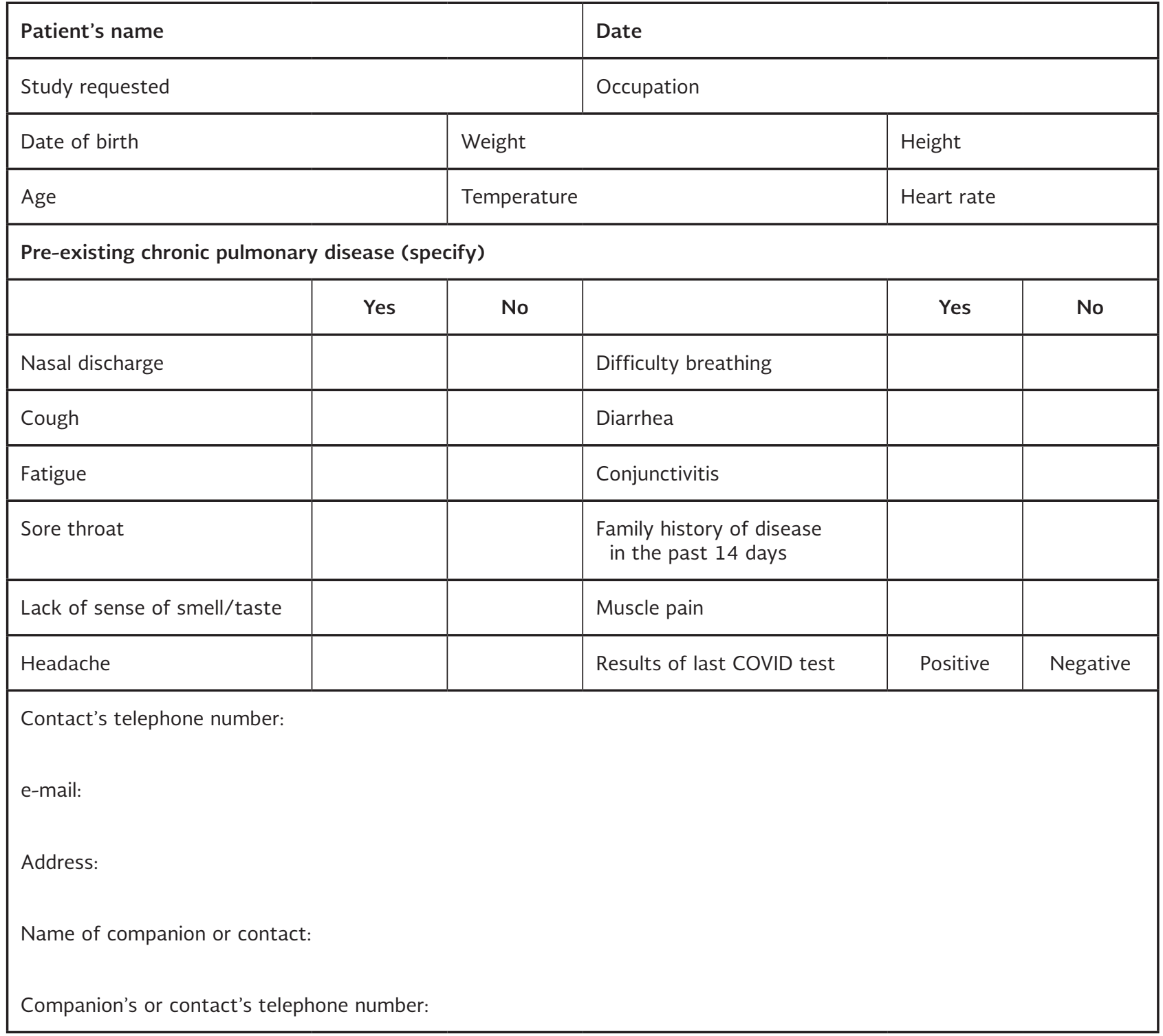

